\title{
Utilization of clinical tools to understand health-care differences of the Discovery Health population
}

\author{
T Mosendane*, A S Persadh, R Jabaar, B Ruff \\ From 26th Patient Classification Systems International (PCSI) Working Conference \\ Munich, Germany. 15-18 September 2010
}

\section{Introduction}

Various clinical tools exist that categorize health-care data into homogenous cohorts. The tools contribute to the understanding of health-care experiences. The tools described below are used in understanding the Discovery Health population.

At a patient level, the John Hopkins Adjusted Clinical Groups (ACG) case-mix system identifies common combinations of disease that impact on each other to increase an individual's risk. The tool is thus robust not only in categorizing patient illness, but also in analyzing health-care utilization and cost.

At an episode of care level, the Discovery Episode grouper (DEG) uses ICD-10 coded data to define episodes. These episodes provide a means for assessing health-care quality and cost.

At the hospital level the Diagnosis Related Group (DRG), a patient classification system, provides an understanding of the costs incurred by measuring the case-mix index of a hospital.

Using the ACG, DEG and DRG, Discovery Health data can be segregated into various resource bands. Highcost members can be identified, and the costs incurred by different providers assessed.

Studies done in various regions in the United States have shown that Medicare spending varies in different areas across the country. Stephan Zuckerman explains that "geographic differences in Medicare spending are not necessarily evidence of inefficiency in health care," and that " $29 \%$ of the differences can be attributed to health, but 33\% remains unexplained".

Clinical Risk Management, Health Insurance, Johannesburg, Gauteng, South Africa
Using region as a starting point, the aim of this project is to understand how much of the differences in health-care cost identified can be explained using the clinical tools. This explainable portion is due to the difference in population demographics and disease burden within different regions. Possible explanatory factors for the residual differences will be explored, with regional differences forming the starting point of the study.

\section{Methods}

Assess and understand the disease burden in various regions by categorizing members into different resource utilization bands (RUBs) using the ACGs.

Identify diseases that exist within the RUBs using the DRGs for hospital cases, DEG for separate episodes, and the Discovery Health Label Matrix for a combined episode view.

Adjust for differences in disease burden and episodes of care in the different provinces, define other factors contributing to differences in health-care costs, leaving an unexplained inefficiency/efficiency cost per province to be explained.

\section{Results}

RUB distributions were as follows: Free State had the highest number of RUB 5 members (2.3\%), followed by Gauteng (1.5\%), Mpumalanga and North West (1.4\%), Limpopo, Northern Cape and Eastern Cape (1.3\%), KwaZulu Natal (1.2\%) and Western Cape (1.1\%).

The distribution of RUB 4 members in the country was $7.5 \%$ in the Free State, $7.3 \%$ in Gauteng, $6.2 \%$ in Mpumalanga, 6\% in Eastern Cape, 5.9\% in North West and Northern Cape, 5.8\% in KwaZulu Natal and Limpopo and $5.4 \%$ in the Western Cape. 
The majority of RUB 3 members are found in Gauteng (42.6\%), with Eastern Cape (38.8\%), Free State (38.6\%), Mpumalanga (37.0\%), KwaZulu Natal (36.2\%), Western Cape (35.8\%), North West (34.4\%), Northern Cape (34.1\%) and Limpopo (33.7\%) following.

RUB 2 users were distributed in Mpumalanga (22.3\%), North West (22.2\%), Gauteng (21.4\%), Limpopo (21.2\%), Eastern Cape (21.1\%), KwaZulu Natal (21.0\%), Western Cape $(20.8 \%$,), Northern Cape $(20.1 \%)$ and Free State (19.9\%).

Members who were considered to be healthy users and categorized into RUB 1 were $17.0 \%$ in the Western Cape, $16.8 \%$ in the Eastern Cape and KwaZulu Natal, $16.5 \%$ in the Northern Cape, $16.2 \%$ in Limpopo, $15.9 \%$ in Mpumalanga, $15.5 \%$ in North West, $15.4 \%$ in Gauteng and $14.5 \%$ in the Free State. The highest numbers of non-users were found in Northern Cape (22.2\%). Limpopo had $21.8 \%$ and North West had $21.0 \%$ of nonusers. In Western Cape and KwaZulu Natal, 19.8\% and $19.0 \%$ of non-users were found, respectively. Just over $17 \%$ of non-users were in Mpumalanga (17.3\%) and Free State (17.2\%), and the lowest number of non-users was distributed with Gauteng (11.8\%).

After adjusting for the different RUB distribution of patients in different provinces, costs for both Gauteng and Free State were higher than that predicted by $4 \%$ and $2 \%$, respectively. The costs for Gauteng and Free State were also above the average cost due to the high proportion of RUB 4 and RUB 5 members. Further investigation is required to understand this residual.

\section{Conclusions}

There are distinct geographical differences within South Africa, with higher costs incurred in higher-cost areas. Further analyses are underway to obtain a greater understanding of other factors that may be contributing to the unexplained differences in health-care costs experienced by different provinces.

Published: 6 October 2010

doi:10.1186/1472-6963-10-S2-A18

Cite this article as: Mosendane et al:: Utilization of clinical tools to understand health-care differences of the Discovery Health population. BMC Health Services Research 2010 10(Suppl 2):A18.

\section{Submit your next manuscript to BioMed Central} and take full advantage of:

- Convenient online submission

- Thorough peer review

- No space constraints or color figure charges

- Immediate publication on acceptance

- Inclusion in PubMed, CAS, Scopus and Google Scholar

- Research which is freely available for redistribution

Submit your manuscript at www.biomedcentral.com/submit 